\title{
Underlying Mechanisms and Therapeutic Strategies for Bisphosphonate- Related Osteonecrosis of the Jaw (BRONJ)
}

\author{
Yasuo Endo, ${ }^{*, a}$ Hiroyuki Kumamoto, ${ }^{b}$ Masanori Nakamura, ${ }^{c}$ Shunji Sugawara, ${ }^{d}$ \\ Teruko Takano-Yamamoto, ${ }^{e}$ Keiichi Sasaki, ${ }^{f}$ and Tetsu Takahashi ${ }^{a}$ \\ ${ }^{a}$ Division of Oral and Maxillofacial Surgery, Graduate School of Dentistry, Tohoku University; \\ Sendai 980-8575, Japan: ${ }^{b}$ Division of Oral Pathology, Graduate School of Dentistry, Tohoku \\ University; Sendai 980-8575, Japan: ${ }^{\circ}$ Department of Oral Anatomy and Developmental Biology, \\ School of Dentistry, Showa University; 1-5-8 Hatanodai, Shinagawa-ku, Tokyo 142-8555, Japan: \\ ${ }^{d}$ Division of Oral Molecular Regulation, Graduate School of Dentistry, Tohoku University; Sendai \\ 980-8575, Japan: ${ }^{e}$ Division of Orthodontics and Dentofacial Orthopedics, Graduate School of \\ Dentistry, Tohoku University; Sendai 980-8575, Japan: and ${ }^{f}$ Division of Advanced Prosthetic \\ Dentistry, Graduate School of Dentistry, Tohoku University; Sendai 980-8575, Japan.
}

Received December 27, 2016; accepted March 9, 2017

\begin{abstract}
Bisphosphonates (BPs), with a non-hydrolysable P-C-P structure, are cytotoxic analogues of pyrophosphate, bind strongly to bone, are taken into osteoclasts during bone-resorption and exhibit long-acting anti-bone-resorptive effects. Among the BPs, nitrogen-containing BPs (N-BPs) have far stronger anti-boneresorptive effects than non-N-BPs. In addition to their pyrogenic and digestive-organ-injuring side effects, BP-related osteonecrosis of jaws (BRONJ), mostly caused by N-BPs, has been a serious concern since 2003. The mechanism underlying BRONJ has proved difficult to unravel, and there are no solid strategies for treating and/or preventing BRONJ. Our mouse experiments have yielded the following results. (a) N-BPs, but not non-N-BPs, exhibit direct inflammatory and/or necrotic effects on soft tissues. (b) These effects are augmented by lipopolysaccharide, a bacterial-cell-wall component. (c) N-BPs are transported into cells via phosphate transporters. (d) The non-N-BPs etidronate (Eti) and clodronate (Clo) competitively inhibit this transportation (potencies, $\mathrm{Clo}>\mathrm{Eti}$ ) and reduce and/or prevent the $\mathrm{N}$-BP-induced inflammation and/or necrosis. (e) Eti, but not Clo, can expel N-BPs that have accumulated within bones. (f) Eti and Clo each have an analgesic effect (potencies, Clo $>$ Eti) via inhibition of phosphate transporters involved in pain transmission. From these findings, we propose that phosphate-transporter-mediated and inflammation/infection-promoted mechanisms underlie BRONJ. To treat and/or prevent BRONJ, we propose (i) Eti as a substitution drug for $\mathrm{N}$-BPs and (ii) Clo as a combination drug with N-BPs while retaining their anti-bone-resorptive effects. Our clinical trials support this role for Eti (we cannot perform such trials using Clo because Clo is not clinically approved in Japan).
\end{abstract}

Key words bisphosphonate; osteonecrosis; inflammation; etidronate; clodronate

\section{INTRODUCTION}

Research on bisphosphonates (BPs) began with studies of inorganic pyrophosphate (PPi) by Fleisch and colleagues. ${ }^{1)}$ Since then, and despite such side effects as influenza-like inflammation (fever and increase in acute-phase proteins) and lesions of digestive organs, BPs have become the most widely used drugs for bone-metastatic cancers (breast, prostate, and lung cancers), multiple myeloma, osteoporosis and osteogenesis imperfecta. In 2003, however, osteonecrosis of the jaw (ONJ) by BPs was reported. ${ }^{2,3)}$ Since that time, many cases of such BP-related osteonecrosis of the jaw (BRONJ) have been added to the literature, and the number is increasing. $\left.{ }^{4}\right) \mathrm{BPs}$ accumulate within bones upon repeated administration. So, if BPs continue to be prescribed at the present rate, BRONJ cases may continue to increase. BRONJ is resistant to current clinical treatments and no solid ways have been established to prevent it. Although oral infection and dental treatments, including tooth extraction, are thought to be BRONJ-promoting factors, details remain elusive. In the aging society, anti-boneresorptive drugs are very important for the treatment and/or prevention of osteoporosis. Consequently, BRONJ is a problem in urgent need of a solution. Here, we review results we and others have obtained from animal experiments and clinical studies, and we propose mechanisms that might underlie BRONJ as well as strategies that might be effective for the treatment and prevention of BRONJ.

\section{NITROGEN-CONTAINING BPs (N-BPs) AND NON- NITROGEN-CONTAINING BPs (NON-N-BPs)}

BPs, chemicals with a non-hydrolysable P-C-P bond, are analogues of PPi, which has a hydrolysable P-O-P bond (Fig. 1). Many derivatives have been synthesized by modifying the central carbon and they are being applied widely in clinical settings. Interestingly, the BPs that have a nitrogen-containing side-chain (abbreviated as N-BPs) exhibit far stronger antibone-resorptive effects than the BPs that lack such a nitrogencontaining side-chain (non-N-BPs). The relative potencies of the anti-bone-resorptive effects of BPs are shown in Fig. 1, in which the potency of etidronate (Eti) is expressed as 1.0. BPs with high potencies have lower clinical doses (Table 1). Both $\mathrm{N}-\mathrm{BPs}$ and non-N-BPs bind strongly to bone hydroxyapatite (Table 2). Thus, they accumulate within bones upon repeated 


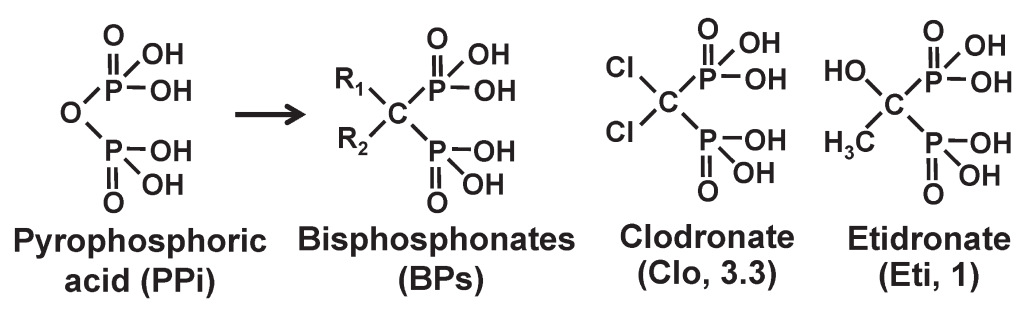<smiles>O=C(O)P(=O)(O)O</smiles>
Phosphonofor- mate (PFA)<smiles>CC(F)(F)COP(=O)(O)C(O)(CCN)P(=O)(O)O</smiles><smiles>COC(=O)OC(O)(Sc1ccc(Cl)cc1)P(=O)(O)O</smiles><smiles>NCCCC(O)(P(=O)(O)O)P(=O)(O)O</smiles>

Alendronate (Ale, 1,000)<smiles>O=P(O)(O)C(O)(Cn1ccnc1)P(=O)(O)O</smiles>
(Zol, 10,000)<smiles>COC(C)O[Na]</smiles>

Fig. 1. Structure of Bisphosphonates (BPs) and Related Substances

Bisphosphonates (BPs), with a non-hydrolysable P-C-P structure, are analogs of pyrophosphate (PPi), which has a hydrolysable P-O-P structure. There are two types of BPs, the nitrogen-containing BPs (N-BPs) and the non-nitrogen-containing BPs (non-N-BPs). Phosphonoformic acid (PFA) is an inhibitor of the phosphate transporter SLC34, although at higher concentrations it inhibits SLC20, too (see Section 7). For each BP, its abbreviation and the relative potency of its anti-bone-resorptive effect are shown within parentheses (that of Eti being given the value 1) (refs. 5, 6).

administration. ${ }^{5)}$ Although the rank orders of affinity of BPs for hydroxyapatite vary among published reports, the affinity of Clo is always the lowest (Table 2).

\section{MECHANISMS UNDERLYING THE ANTI-BONE- RESORPTIVE EFFECTS OF N-BPs AND NON-N-BPs}

In 1992, Amin et al., using rat liver homogenate, reported that Ale and Pam, but not Eti and Clo, inhibit enzymes involved in the synthesis of farnesyl pyrophosphate (FPP) from mevalonate $^{18)}$ (Fig. 2). This finding, despite not initially attracting much attention, has come to be considered important in the inhibitory effects of N-BPs on osteoclasts, and details of this inhibition have been clarified ${ }^{19-21)}$ (Fig. 2). Within osteoclasts, N-BPs inhibit FPP synthase and reduce the amount of FPP (Fig. 2). This reduction results in decreased prenylation (geranylgeranylation and farnesylation) of low-molecularweight G-proteins (such as Ras, Rho and Rab) and thus reduces various types of signal transmission mediated by these proteins. In addition, the inhibition of FPP-synthase results in an increase in isopentenyl pyrophosphate (IPP), and the increased IPP binds to AMP and converts it to a cytotoxic molecule ApppI [abbreviation of triphosphoric acid 1-adenosin-5'-yl ester 3-(3-methylbut-3-enyl)ester]. These effects of N-BPs within osteoclasts are now considered to be the mechanism underlying the anti-bone-resorptive effects of N-BPs. ${ }^{20,22)} \mathrm{On}$ the other hand, within osteoclasts, non-N-BPs are converted to cytotoxic ATP analogues (still not identified) and by this means also inhibit osteoclasts. ${ }^{19,20)}$ Hence, the mechanisms by which N-BPs and non-N-BPs inhibit osteoclasts are not the same.
4. INFLAMMATORY, INTERLEUKIN (IL)-1 PRODUCING AND NECROTIC EFFECTS OF N-BPs

4.1. Inflammatory Effects It has been shown that the non-N-BP Clo, when encapsulated within liposomes and then intravenously injected into mice, can eliminate macrophages from tissues. ${ }^{23,24)}$ About 25 years ago, we hypothesized that macrophages might play important roles in the mechanism by which the histamine-forming enzyme, histidine decarboxylase (HDC), is induced by lipopolysaccharide (LPS, a cell-wall component of Gram-negative bacteria). At that time, various BPs-such as Ale and other N-BPs, which exhibit far more potent anti-bone-resorptive activities than Clo-were already available. Therefore, we expected that even an intraperitoneal (not intravenous) injection into mice of a large amount of such a potent N-BP by itself (i.e., without encapsulating it into liposomes) might decrease the macrophages in tissues and hence reduce HDC-induction by LPS. However, to our surprise, Ale did not reduce such HDC-induction, and nor did other N-BPs. On the contrary, they not only augmented HDC-induction, but by themselves induced HDC. Moreover, they increased macrophages, granulocytes and even osteoclasts. ${ }^{25)}$ These findings (made 10 years before the first report of BRONJ) puzzled us and gave us a strong motive to study BPs further. Over the next few years, we found that intraperitoneal injection of N-BPs induces various types of inflammation and inflammation-related responses in mice, such as hypertrophy of the spleen, atrophy of the thymus, hypoglycaemia, ascites and accumulation of exudate in the thorax, an increase in the number of macrophages and/or granulocytes in the peritoneal cavity, aggravation of collagen-induced arthritis and reduced erythropoiesis in bone marrow. ${ }^{25-29)}$ 
Table 1. Main Preparations of BPs

\begin{tabular}{|c|c|c|c|c|}
\hline Generic name & Potency $^{a}$ & Proprietary name (form) & Dose $(\mathrm{mg} / \mathrm{use})^{b)}$ and prescription $\left.{ }^{c}\right)$ & Major indications \\
\hline Etidronate $^{(d)}$ & 1.0 & Didronel (tablet) & 200-1000 once/d & $\mathrm{OP}, \mathrm{PD}, \mathrm{PO}$ \\
\hline Clodronate ${ }^{d) \#}$ & 3.3 & Bonfes/Clasteo/Loron (tablet or capsule) & $400-1600$ once/d & $\mathrm{BMC}, \mathrm{MM}$ \\
\hline Tiludronate ${ }^{d) \#}$ & 3.3 & Skelid (tablet) & 400 once/d & PD \\
\hline Pamidronate $^{e)}$ & 33 & Aredia (injection) & $30-45$ or 90 once $/ 4 w$ & $\mathrm{BMC}, \mathrm{MM}$ \\
\hline \multirow[t]{2}{*}{ Alendronate ${ }^{e)}$} & 1000 & Fosamac/Bonaron (tablet) & 5 once $/ \mathrm{d}, 35$ once $/ \mathrm{m}$ & OP \\
\hline & & Teiroc/Onclast (injection) & $10-20$ once/w & $\mathrm{BMC}, \mathrm{MM}$ \\
\hline Incadronate $e^{e)}$ & 1000 & Bisphonal (injection) & 10 once/w & $\mathrm{BMC}, \mathrm{MM}$ \\
\hline Risedronate $^{e)}$ & 3300 & Benet/Actonel (tablet) & $\begin{array}{c}2.5 \text { once } / \mathrm{d}, 17.5 \text { once/d (for } 8 \mathrm{w} \text { ) } \\
17.5 \text { once } / \mathrm{w}, 75 \text { once } / \mathrm{m}\end{array}$ & $\mathrm{OP}, \mathrm{PD}$ \\
\hline Ibandronate $e^{e)}$ & 10000 & Bonviva (injection) & 1 once $/ \mathrm{m}$ & OP \\
\hline Zoledronate $^{e)}$ & 10000 & Zometa (injection) & 4 once/w or $\mathrm{m}$ & $\mathrm{BMC}, \mathrm{MM}$ \\
\hline Minodronate $^{e)}$ & 10000 & Recalbon/Bonoteo (tablet) & 1 once $/ \mathrm{d}, 50$ once $/ \mathrm{m}$ & OP \\
\hline
\end{tabular}

a) Relative anti-bone-resorptive activity (ABRA) per molecular weight of each BP (refs. 5, 6). b) Approved doses (in Japan, except for clodronate and tiludronate). c) BP administration schedules: (i) Didronel tablet (one cycle): 200 or $400 \mathrm{mg}$ between meals once a day for 2 weeks and then 10-12 weeks' rest. (ii) Other tablets: once a day upon getting up, ingested with $180 \mathrm{~mL}$ or more water, not lying down for at least $30 \mathrm{~min}$, and not ingesting anything other than water. (iii) Zometa injection: diluted with $100 \mathrm{~mL}$ of saline or dextrose-saline, then dripped for at least $15 \mathrm{~min}$. (iv) Other injections: diluted with $500 \mathrm{~mL}$ of saline or dextrose-saline, then dripped for at least $4 \mathrm{~h}$. $d$ ) non-N-BPs. e) N-BPs. "Not approved in Japan. OP, osteoporosis; PO, parosteosis; PD, Paget disease; BMC, bone metastatic cancer; MM, multiple myeloma.

Table 2. Properties of BPs

\begin{tabular}{lc}
\hline \hline Order of potency & References \\
\hline Anti-bone-resorptive effects: & \\
Min $=$ Zol $=$ Iba $>$ Ris $>$ Ale $>$ Pam $>$ Til $=$ Clo $>$ Eti & $5,6)$ \\
Our data from BP-band assay & \\
$\quad$ Zol $>$ Ris $>$ Ale $>$ Pam & $7)$ \\
$\quad$ Ale $>$ Clo $>$ Eti & $8)$ \\
$\quad$ Min $\geq$ Zol $>$ Iba $\geq$ Ale & $9,10)$ \\
Affinity for hydroxyapatite: & $11)$ \\
Ale $>$ Zol $>$ Pam $>$ Ris $>$ Eti $>$ Iba $>$ Til $>$ Clo & $12)$ \\
Zol $>$ Ale $>$ Iba $>$ Ris $>$ Eti $>$ Clo & $13)$ \\
Pam $>$ Ale $>$ Eti $>$ Zol $>$ Iba $>$ Min $>$ Ris $>$ Clo & \\
Inhibition of FPP-synthase $($ in vitro $):$ & $6)$ \\
Zol $=$ Min $=$ Iba $>$ Ris $>$ Ale $>$ Pam & \\
Inflammatory $/$ necrotic effects in mice: & $7,10,14)$ \\
Min $>$ Zol $>$ Iba $\geq$ Pam $\geq$ Ale $>$ Ris & $10,15)$ \\
Inhibition of N-BP-mediated inflammation/necrosis: & $16,17)$ \\
Clo $>$ Eti $>$ Til &
\end{tabular}

4.2. IL-1-Producing Effects IL-1 is a typical inflammatory cytokine, and there are two types, IL- $1 \alpha$ and IL- $1 \beta$. Each is produced as a $31 \mathrm{kDa}$ precursor and converted to its $17 \mathrm{kDa}$ mature form via enzymatic cleavage. Although the aminoacid-sequence homology between IL- $1 \alpha$ and IL- $1 \beta$ is low (27\%), these cytokines bind to common receptors and both are pyrogenic in humans. IL- $1 \alpha$ is present in various normal cells as pro-IL- $1 \alpha$ and is released when the cells are damaged, while IL- $1 \beta$ is not present in normal cells but is produced in limited types of cells including macrophages, monocytes and dendritic cells in response to inflammatory stimuli such as stimulation of Toll-like receptors (TLRs) and IL-1 receptors. ${ }^{30)}$ Pro-IL- $1 \alpha$ is active itself and is present in nucleus and cell membranes, while pro-IL-1 $\beta$ becomes the active form after cleavage by caspase- 1 and is then released from the cells. ${ }^{31)}$

LPS is a potent inducer of both IL- $1 \alpha$ and IL- $1 \beta$. Intravenous or intraperitoneal injection of LPS or IL-1 induces HDC even at a very low dose. ${ }^{32-35)}$ In mice given N-BPs by intraperitoneal injection, we found that (i) the induction of HDC by LPS is markedly augmented, and this augmentation is due to an increased production of IL- $1 \alpha$ and IL- $1 \beta,^{36,37)}$ and (ii) in a mouse strain deficient in both IL- $1 \alpha$ and IL- $1 \beta$ (IL-1-KO mice), the inflammatory reactions (including HDC induction) induced by intraperitoneal or local injection of N-BPs are very weak. ${ }^{14,37)}$ Strangely, although we could not detect IL-1 in the blood after injection of an N-BP alone, we could detect IL-1 $\beta$ in the liver, spleen and lung. ${ }^{38,39)}$ The reason for IL-1 $\beta$ being undetectable in the blood seems to lie in our demonstration that although N-BPs increase pro-IL- $1 \beta$ within cells, activation of caspase- 1 is insufficient for IL- $1 \beta$ to be released from the cells. ${ }^{39)}$

Fever occurs in about $30 \%$ of patients receiving an intravenous N-BP for the first time, ${ }^{40)}$ with fatalities occurring among children due to the fever. ${ }^{41)}$ By contrast, the non-N-BP Clo does not exhibit such an effect. ${ }^{40)}$ Interestingly, fever does not occur in patients given second or repeated intravenous N-BPs or in patients previously given intravenous Clo. ${ }^{40)}$ IL-1 is a potent endogenous pyrogen in humans. As described above, in mice given N-BPs, IL-1 production is markedly augmented. ${ }^{36}$ ) So, we suppose that in patients with infection, augmented production of IL- $1 \beta$ and activation of caspase- 1 might be involved in the N-BP-induced fever. If the major cells producing IL- $1 \beta$ are osteoclasts, it seems likely that a decrease in the number of active osteoclasts occurs sometime after the initial injection of N-BPs or Clo, and thus the second injection does not produce sufficient IL-1 $\beta$ to induce fever. However, this hypothesis remains to be examined.

4.3. Necrotic Effects Around 1990, when we started to study BPs, there was a report indicating that N-BPs (called aminobisphosphonates at that time), but not Clo, induce necrosis at the site of injection (in rat skin). ${ }^{42}$ N-BPs, when injected into the ear-pinnas of mice, produce inflammatory swelling at the injection site, while at high concentrations they produce necrosis at that site. ${ }^{7,14}$ Although the inflammatory swelling induced by low concentrations of N-BPs is much smaller in IL-1-KO mice than in wild-type mice, the extent of the necrosis induced by higher concentrations of N-BPs is similar between these two strains, ${ }^{14)}$ suggesting that IL-1 is involved in the N-BP-induced inflammation, while other toxic factor(s) may be important in the N-BP-induced necrosis.

4.4. Relationship between Inflammation/Necrosis and 


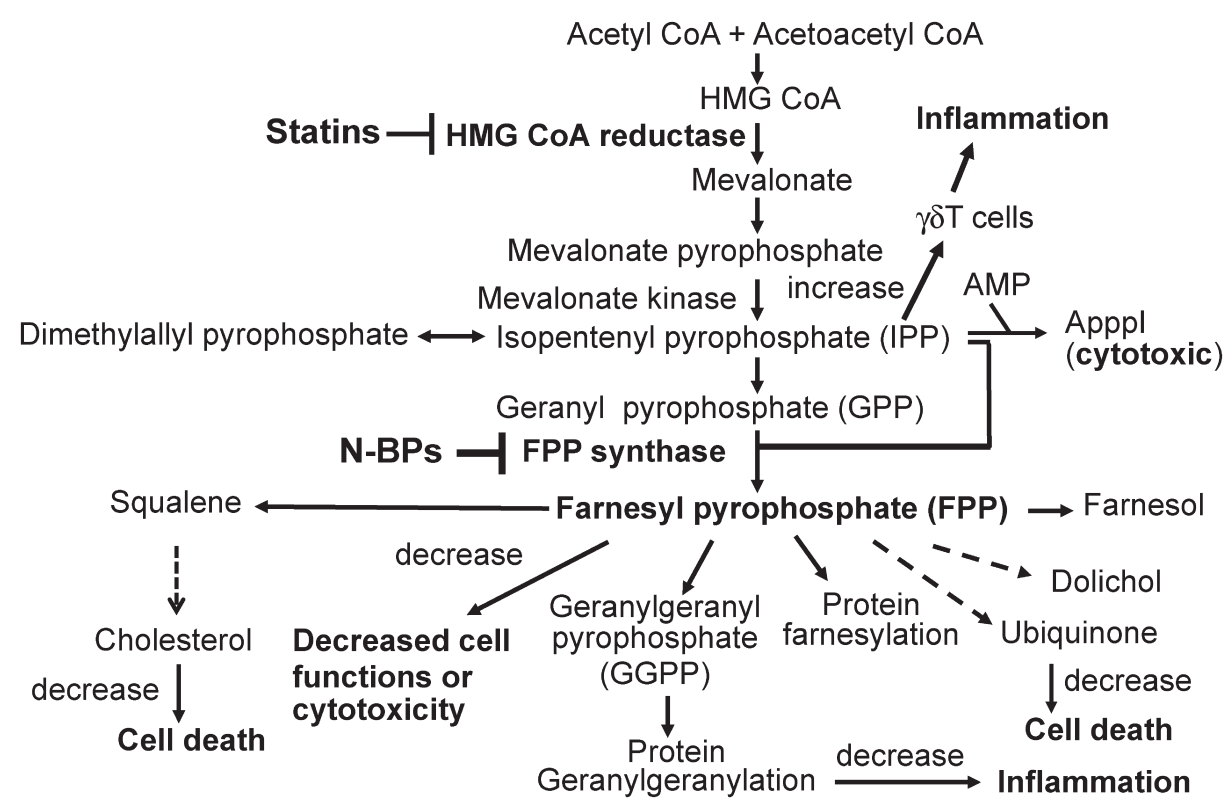

Fig. 2. Inflammatory/Cytotoxic Effects of N-BPs and the Cholesterol Biosynthesis Pathway

N-BPs inhibit FPP-synthase in cholesterol biosynthesis. Decrease in FPP results in decreased functions of many cell-types, inflammation (including IL-1 production), cytotoxicity and cell-death. Inhibition of FPP-synthase results in an increase in IPP that activates a population of $\gamma \delta$ T cells in humans (see text). Statins (drugs used to reduce cholesterol) inhibit HMG-CoA-reductase. See text for details.

Cholesterol Biosynthesis Concerning the relationship between N-BP-induced inflammation and cholesterol biosynthesis, the following findings have been reported. (a) Inhibition of FPP synthase results in an increase in IPP, with the IPP directly or indirectly stimulating $\mathrm{V} \gamma 2 \mathrm{~V} \delta 2 \mathrm{~T}$-cells to produce interferon- $\gamma$ (IFN- $\gamma$ ) and tumor necrosis factor (TNF) and possibly inducing acute inflammatory reactions, including fever. ${ }^{43,44)}$ However, it is notable that a population of $\gamma \delta \mathrm{T}$ cells that is stimulated by N-BPs has not been found in mice or in other non-primates. ${ }^{45,46)}$ (b) A decrease or defect in mevalonate kinase in cholesterol biosynthesis results in a reduced geranylgeranylation of proteins (Fig. 2), and this reduction stimulates the production of IL-1, leading to profound chronic inflammatory diseases in children. ${ }^{47}$

It should be noted that inhibition of FPP synthase leads to reduced synthesis not only of cholesterol but also of farnesol, dolichol and ubiquinone (Fig. 2). Cholesterol is an indispensable constituent of cell membranes, while ubiquinone is a stabilizer of the cell membrane, an anti-oxidant and a constituent of the respiratory chain in mitochondria. In addition, the pathway for cholesterol synthesis generally resides in all eukaryotic cells. Indeed, N-BPs exhibit cytotoxicity in vitro not only against osteoclasts but also against a variety of other cells ${ }^{48}$ ) and Zol has been reported to augment the cytotoxic effect of TNF against vascular endothelial cells. ${ }^{49,50)}$ As described in Section 4.1., N-BPs induce HDC in various tissues in mice and also augment HDC-induction by LPS, and vascular endothelial cells are supposed to be the major cells in which HDC is induced. ${ }^{26,51)}$ Thus, inhibition of FPP synthase results in toxic effects via a variety of effects on a variety of cells.

Statins, drugs that inhibit hydroxymethylglutaryl-CoA (HMG-CoA) reductase (Fig. 2) and reduce the blood level of cholesterol, are inhibitory against the inflammatory effects of N-BPs. ${ }^{52)}$ Interestingly, however, they promote N-BP-induced necrosis in ear-pinnas. ${ }^{14)}$ It has also been reported that statins induce apoptosis in vascular endothelial cells and keratino- cytes. $^{53,54)}$

\section{EFFECTS OF ETI AND CLO ON THE INFLAM- MATORY/NECROTIC EFFECTS OF N-BPs}

As described above, N-BPs exhibit potent inflammatory and necrotic effects, while the non-N-BPs Eti and Clo exhibit no such effects. We observed twenty years ago, in a mouse model of arthritis, that N-BPs augment the arthritis, whereas Clo improves it. ${ }^{28)}$ Later, we found in various experiments that Eti and Clo inhibit not only the inflammation but also the necrosis induced by N-BPs, and that the inhibitory effect of Clo is more potent than that of Eti. ${ }^{7-10,14,15,27,55,56)}$ For example, although $\mathrm{Zol}$ (one of the most potent anti-bone-resorptive $\mathrm{N}-\mathrm{BPs}$ ) induces severe inflammation and necrosis in mouse ear-pinnas, such effects of $2 \mathrm{~mm} \mathrm{Zol}$ are completely prevented by $8 \mathrm{~mm} \mathrm{Eti}{ }^{14)}$ and those induced by $4 \mathrm{~mm}$ Zol are completely prevented by $4 \mathrm{~mm}$ Clo. ${ }^{7)}$ The non-N-BP Til (Fig. 1) also reduces Zol-induced inflammation, but its effect is much weaker than that of Eti. ${ }^{10)}$

In vitro experiments have confirmed the following. (i) One hundred micromol Ale directly stimulates RAW 264 cells (murine macrophage-like cells) to produce pro-IL- $1 \beta$, and $1 \mu \mathrm{M}$ Clo inhibits this effect. ${ }^{39)}$ (ii) There was no clear difference between tumour cells and non-tumour cells in their sensitivity to the cytotoxicity of Zol. In contrast, Eti was not toxic at $1-100 \mathrm{~mm}$ in any of the cells tested, and Eti reduced the cytotoxicity of Zol in many cell-types. ${ }^{48)}$

\section{EFFECTS OF ETI AND CLO ON THE ANTI-BONE- RESORPTIVE EFFECTS OF N-BPS}

6.1. BP-Band We noticed that a few weeks after a single intraperitoneal injection of an N-BP into young (4- to 5-week-old) mice, radiography of their tibias reveals a clear sclerotic band (tentatively called "BP-band"), reflecting an 
inhibition of bone-resorption. ${ }^{8,55)}$ As shown in Fig. 3A, N-BPs produce clearly evident BP-bands at $0.1 \mathrm{~mm}$, while Clo produces a detectable BP-band at $10 \mathrm{~mm}$ and Eti produces a BP-band at $50 \mathrm{~mm}$ but not at $10 \mathrm{~mm}$ (data not shown). The site at which such a BP-band is formed is the growth plate at the time of N-BP injection. Analysis of radiography results confirmed that the BP-band is a good index of the anti-bone-resorptive effects of BPs, allowing rapid and simple estimation of such effects. $^{7,56)}$ Incidentally, BP-bands are observed in human children, too. ${ }^{57,58)}$

6.2. Contrasting Effects of Eti and Clo on the Antibone-Resorptive Effects of N-BPs The effects of Clo and Eti on BP-band formation by N-BPs (Ale, Ris and Zol), with which they were co-injected, are also shown in Fig. 3. The BP-bands formed following injection of a combination of Clo and an N-BP are similar to those formed by each N-BP alone (Fig. 3A). However, a combination of Eti and an N-BP markedly reduced the N-BP-induced BP-band formation (Fig. $3 \mathrm{~B})$. These results indicate that while the anti-bone-resorptive effects of N-BPs are not profoundly affected by Clo, they are strongly inhibited by Eti. ${ }^{7,85)}$ We can explain this difference by the difference in the affinities for hydroxyapatite shown by Clo and Eti (Table 2); that is, because the affinity of Clo is very low, its ability to competitively inhibit the binding of N-BPs to bones is weak. On the other hand, because the affinity of Eti is in the middle of the range shown by BPs, its ability to competitively inhibit the binding of N-BPs to bones is stronger. Interestingly, when Eti was injected after $(0.5-16 \mathrm{~h})$ injection of an N-BP, Eti reduced BP-band formation by the $\left.\mathrm{N}-\mathrm{BP},{ }^{14}\right)$ indicating that Eti can expel N-BPs from bone(s) in which they have accumulated.

Hydroxyapatite is more exposed at sites of enhanced boneresorption, such as regions of inflammation or tumour metastasis. BPs, when injected intravenously, bind in large amounts to hydroxyapatite at such sites. Thus, bone scintigraphy, using a ${ }^{99 \mathrm{~m}} \mathrm{Tc}-$ labelled BP, can detect inflammatory or tumour metastatic regions in bones. Using this method, we directly demonstrated that Eti expels N-BPs from bone(s) in which they have accumulated (Fig. 4A) and also that N-BPs accumulate at the inflammatory site in a mouse mandible after tooth extraction
(Fig. 4B). We further observed that BPs accumulate in large amounts in human mandibles at an early stage of BRONJ (Fig. 4C1). As shown in Figs. 4C2 and 4C3, this accumulation is reduced during treatment with Eti (details are given in Section $10)$.

\section{MECHANISM UNDERLYING THE UPTAKE OF N-BPs INTO SOFT-TISSUE CELLS AND THE EFFECTS OF ETI AND CLO}

During bone-resorption, $\mathrm{HCl}$ is released from osteoclasts and dissolves bones, causing BPs that had previously accumulated within the bone to be eluted out. Under such an acidic environment at a bone surface covered by osteoclasts, the polarity of the eluted BPs is low because protons bind to the two phosphoric acid residues of the BPs, thereby making them lipophilic. Thus, the BPs may be taken into osteoclasts in a passive and/or non-specific manner. However, under a neutral environment (i.e., in most soft tissues) BPs, especially non-N-BPs, are highly polarized by loss of their protons, making it hard for them to pass through cell membranes. ${ }^{60)}$ Indeed, when injected intravenously into mice, Pam (an N-BP, Fig. 1), remains in the liver and spleen for a long time, while Eti and Clo are not retained in these tissues at all, although they are retained within bones. ${ }^{61)}$ Hence, under neutral environments $\mathrm{N}$-BPs must be taken into cells via some specific transporters, and inhibition of such transportation might be expected to reduce or prevent the inflammatory/necrotic effects of N-BPs.

Thus, we tested the effects of many substances (including many anionic chemicals and various substances with structures resembling BPs) on the inflammation/necrosis induced by Zol in mouse ear-pinnas. During this study, we noted that phosphonoformic acid (PFA) (Fig. 1) is an inhibitor of phosphate transporters ${ }^{62)}$ and that Eti and Clo inhibit phosphate transporters. ${ }^{63)}$ Three families of phosphate transporters are known (viz. SLC17, SLC20 and SLC34). ${ }^{64-66)}$ SLC20 is distributed widely among various cells. ${ }^{64,66)}$ PFA has been shown to inhibit SLC20 and SLC34. ${ }^{64)}$ Based on the results obtained from our experiments using many substances, we concluded the following. ${ }^{67)}$ (i) N-BPs are taken into cells via SLC20
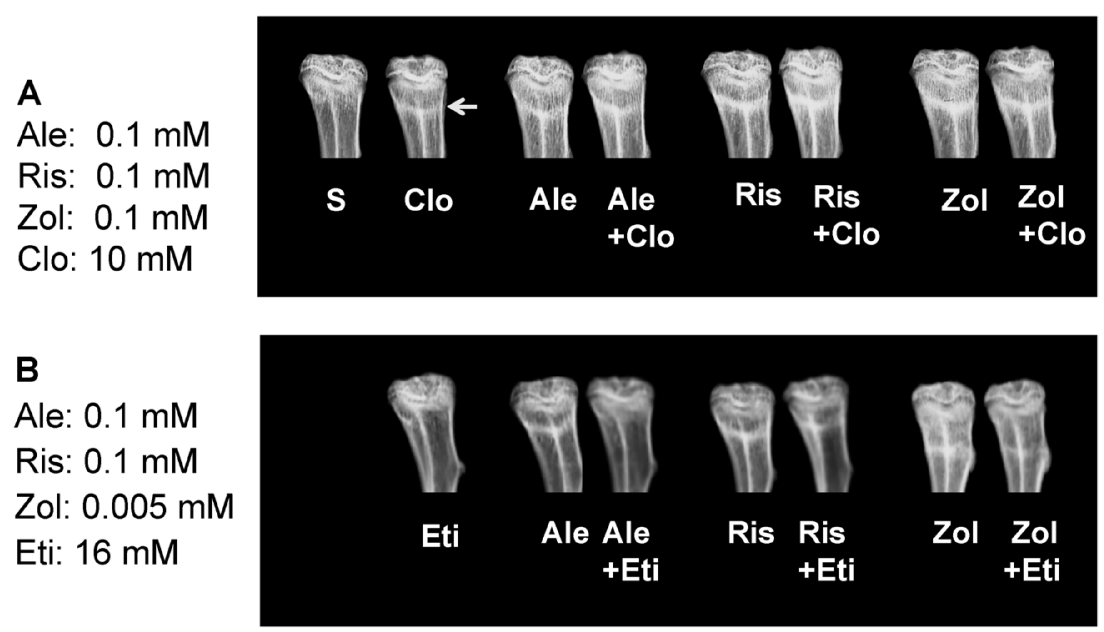

Fig. 3. BP-Band, a Simple Index of the Anti-bone-Resorptive Effects of BPs

(A) Effects of Clo on BP-band formation by N-BPs (Ale, Ris and Zol). Saline (S) or the indicated concentrations of BPs were intraperitoneally injected into young (5-week-old) mice $(0.1 \mathrm{~mL} / 10 \mathrm{~g}$ body weight). Two weeks later, tibias were removed and subjected to X-ray analysis. Arrow shows a Clo-induced BP-band. (B) Effects of Eti on BP-band formation by N-BPs. BPs were injected into young mice as described above and two weeks later (three in the case of Zol), tibias were removed and subjected to X-ray analysis. 

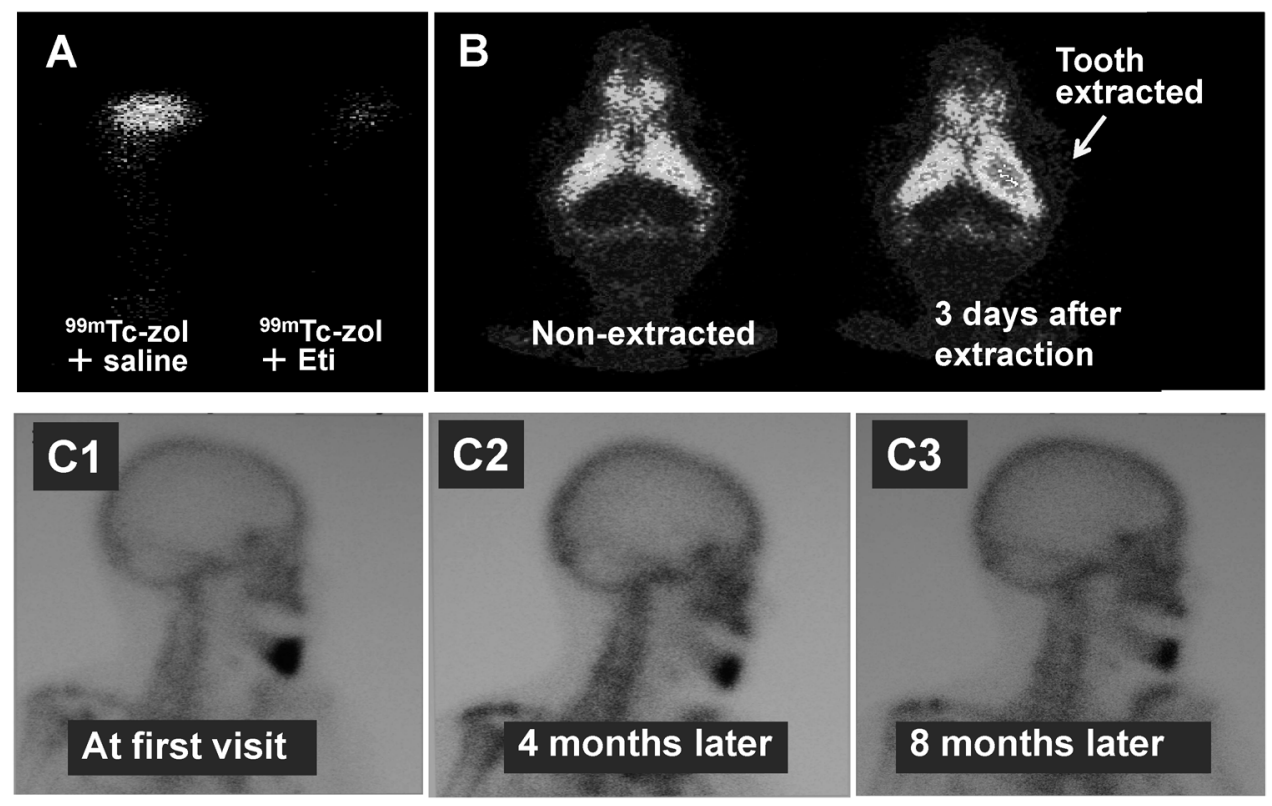

Fig. 4. Bone-Scintigraphy of Mice and BRONJ Patients

(A) ${ }^{99 \mathrm{~m}} \mathrm{Tc}-\mathrm{Zol}(0.05 \mathrm{~mm})$ was intravenously injected into young (5-week-old) $(0.2 \mathrm{~mL} / \mathrm{mouse})$ mice. Then, $30 \mathrm{~min}$ later, Eti ( $\left.2 \mathrm{~mm}\right)$ or saline was injected intravenously into these mice $(0.2 \mathrm{~mL} /$ mouse). The tibias were rapidly removed $1.5 \mathrm{~h}$ after the second injection, and bone scintigraphic images were taken using a gamma camera with a highresolution pinhole collimator. A marked accumulation of ${ }^{99 \mathrm{~m}} \mathrm{Tc}-\mathrm{Zol}$ is seen in the epiphysis of the tibia in the mice not given Eti (ref. 14). (B) Under anaesthesia, a molar was extracted from 12 -week-old mice. Then, $3 \mathrm{~d}$ later, ${ }^{99 \mathrm{~m}} \mathrm{Tc}$-Oxi was intravenously injected into the same mice $(0.2 \mathrm{~mL} / \mathrm{mouse})$. A marked accumulation of ${ }^{99} \mathrm{~m}$ Tc-Oxi is seen around the site of the molar extraction. (C) Bone-scintigraphy of a BRONJ patient during Eti-replacement therapy. Bone-scintigraphy was performed by intravenous injection of ${ }^{99 m} \mathrm{Tc}-O x i$. A progressive shrinkage of the area of accumulation of ${ }^{99 \mathrm{~m}} \mathrm{Tc}-\mathrm{Oxi}$ is seen compared with that at the first visit $(i . e$., the inflammatory area is shrinking) (ref. 59)

and/or SLC34. (ii) PPi and the non-N-BPs Oxi and Med (all three substances are inflammatory/necrotic) are taken in via SLC17. (iii) PFA inhibits SLC20 and SLC34 (but not SLC17) and thus PFA inhibits the inflammatory/necrotic effects of Zol but not those of PPi, Oxi or Med. (iv) Eti and Clo inhibit all of SLC17, SLC20 and SLC34 and thus inhibit the inflammatory/ necrotic effects of Zol as well as those of PPi, Oxi and Med. (v) The order of potencies for inhibition of the inflammatory/ necrotic effects of Zol is Clo $>$ Eti $>$ PFA. These conclusions were supported by experiments using other N-BPs, too. ${ }^{9,10,15)}$ In brief, our view is that N-BPs enter cells via SLC20 and/or SLC34 phosphate transporters, and the non-N-BPs Eti and Clo inhibit this transport and thus reduce or prevent the inflammatory/necrotic effects of N-BPs (Fig. 5).

\section{EXACERBATION OF INFLAMMATORY/NEC- ROTIC EFFECTS OF N-BPs BY INFECTION}

As described in Section 4.2., the HDC induction and IL-1 production caused by LPS is markedly augmented in N-BPpretreated mice. ${ }^{36,37)}$ Moreover, HDC induction by N-BPs is augmented in mice pretreated with LPS. ${ }^{38)}$ In the experiments described in those reports, we used Escherichia coli LPS. In periodontitis, Prevotella intermedia is a prevalent Gram-negative bacterium, and the structure of $P$. intermedia LPS is different from that of $E$. coli LPS. However, our earlier study had demonstrated that the inflammatory effect of $P$. intermedia LPS is also augmented in N-BP-treated mice. ${ }^{68)}$ IL-1 release from macrophages in vitro in the presence of oral bacteria is another effect that is augmented by N-BPs. ${ }^{69}$ Moreover, expression of the LPS receptor TLR4 (Toll-like receptor-4) is augmented by N-BPs (our manuscript in preparation). These findings suggest that infection and N-BPs mutually augment inflammation, and that infection may be causally involved in BRONJ. It is also likely that infection is involved in the fever that is induced by N-BPs when they are intravenously injected for the first time in a given patient (see Section 4.2.).

\section{MECHANISMS UNDERLYING BRONJ}

Our research has shown that N-BPs, but not Eti and Clo, induce inflammation/necrosis at the site of injection, and that the order of potencies for these effects is $\mathrm{Min}>\mathrm{Zol} \gg \mathrm{Iba} \geq \mathrm{Pam} \geq$ Ale $>$ Ris ${ }^{7,9,10,14)}$ (Table 2). In a recent review by Fliefel et al. ${ }^{4}$ among 4119 BRONJ patients the rank order of the N-BPs that caused BRONJ and the number of patients affected were: Zol (intravenous) (2427) $>$ Pam (intravenous) (571) $>$ Ale (oral and intravenous) (523) $>$ Iba (oral) (128). In a recent investigation (from Jan. 2011 to Dec. 2013) by the Japan Academic Society of Oral Maxillofacial Surgery, ${ }^{70)}$ N-BPs were found to have caused 4685 BRONJ cases in Japan. Among those cases, the rank order of the N-BPs that caused BRONJ and the number of cases were: Zol (intravenous) (2261) $>$ Ale (intravenous and oral) (1589) $>$ Ris (oral) (556) $>$ Min (oral) (219) $>$ Pam (intravenous) (54). Min is the newest N-BP developed in Japan for use against osteoporosis and it has been in use since 2011. Even so, Min had already caused 219 BRONJ cases during that short period (up to Dec. 2013). In mice, Min's anti-boneresorptive effect and inflammatory and necrotic effects are as great as, or greater than, those of Zol. ${ }^{9}$ Although precise figures for incidence of BRONJ are not known, these clinical results suggest that the mechanisms proposed to underlie the inflammatory/necrotic effects of N-BPs in mice might be causally involved in BRONJ.

Oral tissues are usually exposed to bacteria. We have shown in a mouse model of arthritis that repeated intraperi- 


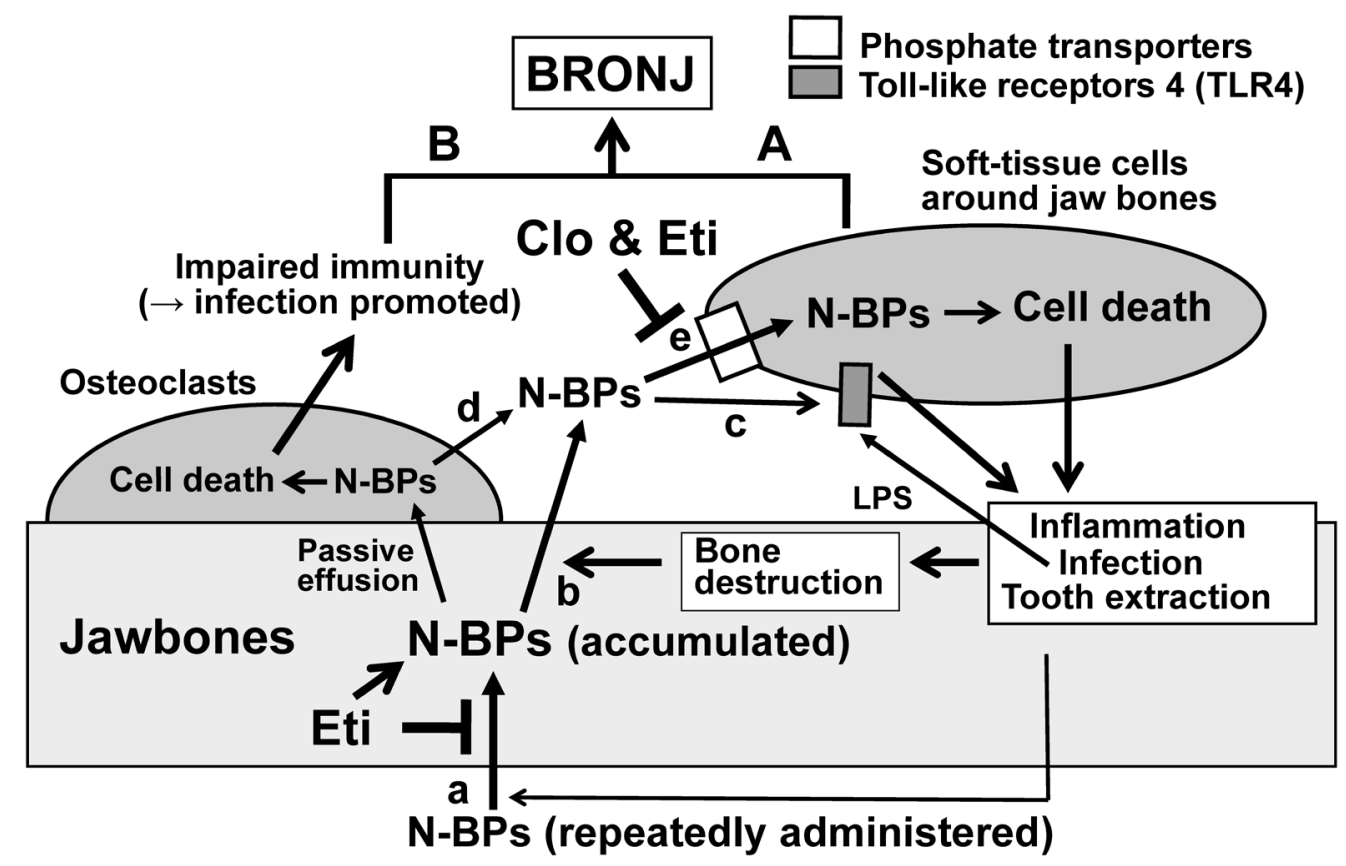

Fig. 5. Mechanisms Underlying BRONJ and the Effects of Eti and Clo: A Proposal

Labels "a" to "e" indicate the following. (a) Accumulation of N-BPs in large amounts in jaw bones upon their repeated administration, and promotion of their accumulation by inflammation (which may be due to infection and/or tooth extraction). (b) Release of the accumulated N-BPs and its promotion by bone destruction. (c) Up-regulation of TLR4 by N-BPs, resulting in augmented inflammation. (d) Release of N-BPs from dead osteoclasts. (e) Uptake of N-BPs (administered or released from jawbones) into cells around jawbones via phosphate transporters. These effects (a-e) may form a "vicious circle" and cause BRONJ (see text for details). Clo and Eti can prevent or limit this vicious circle by inhibiting the intracellular uptake of N-BPs via phosphate transporters. In addition, Eti can inhibit the binding of N-BPs and can expel N-BPs that have already accumulated in jawbones. See text for details.

toneal injection of a low dose of N-BPs results in a marked infiltration of macrophages and granulocytes into joints and an exacerbation of the arthritis, even though N-BPs strongly inhibit osteoclasts. ${ }^{28)}$ In experiments using mouse ear-pinnas, too, N-BPs were found to induce a marked infiltration of granulocytes. ${ }^{59)}$ Monocytes and granulocytes also accumulate in oral tissues in BRONJ patients. ${ }^{71)}$ As shown in Figs. 4B and $\mathrm{C} 1$, inflammation in bones promotes the accumulation of BPs in the same bones. However, it is notable that N-BPs can be detected in saliva obtained from patients who have BRONJ or are at risk of BRONJ, ${ }^{72}$ indicating that $\mathrm{N}$-BPs are released from jaw bones during the necrotic process.

Here, we propose that the following mechanisms may underlie BRONJ: (a) N-BPs accumulate in jawbones upon their repeated administration and this accumulation is promoted by inflammation caused by oral bacteria and/or tooth extraction, (b) the accumulated N-BPs are released by bone destruction caused by infection and/or tooth extraction, (c) TLR4 is upregulated by N-BPs. (d) N-BPs are also released from dead osteoclasts. (e) N-BPs (both administered and released from bones) are taken into soft-tissue cells around jawbones via phosphate transporters, and the N-BPs taken into the softtissue cells induce inflammation and/or cell death by virtue of their cytotoxicity. These effects (a-e) may form a "vicious circle," and this may lead to the spread of the necrosis through jawbones and the soft-tissues around them, resulting in the exposure of the necrotic jawbones (Fig. 5A). In addition, as discussed in Section 13, impaired osteoclast-mediated immunity may also contribute to the promotion of ONJ.

\section{TREATMENT OF BRONJ: ETI AS A SUBSTITUTION DRUG FOR N-BPs}

In addition to antibiotics, analgesics and conventional surgical intervention, several strategies against BRONJ have been proposed..$^{59,73-79)}$ The studies cited for (i) to (iv) in Table 3 are all case reports and have not been confirmed. In contrast, the effectiveness of teriparatide therapy (v) has been repeatedly reported. Although those case reports mostly lack controls, Kim et $a l{ }^{77)}$ having made comparisons with a non-treated group, suggested that teriparatide is significantly beneficial, and that the serum vitamin D concentration may be important for such a beneficial effect. However, it should be noted that teriparatide must be given subcutaneously by the patients themselves (it cannot be given orally), and that teriparatide cannot be employed in BRONJ patients with bone-metastatic cancers (because its tumorigenic property causes it to be contraindicated in such patients). Although the effectiveness of platelet-rich-plasma therapy (vi) has also been repeatedly reported, it has the weakness that the plasma must be prepared from the patients themselves.

As described in Section 6, our experiments in mice revealed that Eti has the ability (a) to expel N-BPs from bone(s) in which they had previously accumulated and (b) to inhibit the inflammatory/necrotic effects of N-BPs by inhibiting their uptake into cells via phosphate transporters (Fig. 5A). Although the anti-bone-resorptive effect of Eti is much weaker than those of N-BPs (Fig. 1), its clinical dose is very large compared to those of N-BPs (Table 1), the doses of N-BPs being $1-50 \mathrm{mg}$, while the dose of Eti is $200-1000 \mathrm{mg}$. That being so, we might expect such a large dose of Eti to produce inhibitory effects in human patients similar to those we observed in mice. Indeed, our clinical trials in two BRONJ patients (given 
oral N-BPs) ${ }^{59)}$ and 25 BRONJ patients (11 patients given oral $\mathrm{N}-\mathrm{BPs}$ and 14 patients given intravenous $\mathrm{N}-\mathrm{BPs})^{79)}$ suggest that Eti treatment promotes or tends to promote the separation and removal of sequestra and thereby promotes the recovery of soft tissues, allowing them to cover the exposed jawbones again. In the latter trial, the effects of Eti were evaluated by comparison with respective control groups (i.e., not-treated with Eti). Incidentally, after such Eti-therapy is terminated, it seems possible to resume N-BP-therapy. ${ }^{79)}$

\section{PREVENTION OF BRONJ: CLO AS A COMBINATION DRUG WITH N-BPS}

As described in Sections 5, 6 and 7, in mice Clo strongly inhibits the uptake of N-BPs into cells via phosphate transporters and it inhibits or prevents the inflammatory/necrotic effects of N-BPs (Fig. 5A). Conveniently, the affinity of Clo for bones is weaker than those of N-BPs (Table 2) and thus its ability to inhibit the binding of N-BPs to bones is also weak (i.e., the inhibitory effect of Clo against the anti-boneresorptive effects of N-BPs is weak). Thus, in human patients it might be expected that a combination of Clo with an N-BP would prevent the inflammatory/necrotic effects of the N-BP, without impairing the latter's potent anti-bone-resorptive effect. However, Clo (unlike Eti) might not expel an N-BP that had previously accumulated in bones because of its low affinity for bones. As the anti-bone-resorptive activity of Clo is 3-times higher than that of Eti, Clo should be suitable as a combination drug with an N-BP. Unfortunately, we cannot examine this issue because Clo is not approved for clinical use in Japan (unless we can collaborate with foreign investigators). Incidentally, if Eti were to be combined with an N-BP, it might inhibit the binding of the N-BP to bone and thereby reduce the anti-bone-resorptive effect of the N-BP.

Outside Japan, Clo, like N-BPs, is being applied not only to osteoporosis but also to bone-metastatic cancers. Intravenous $\mathrm{N}-\mathrm{BPs}$ are reported to exhibit anti-tumour activities via direct and/or indirect effects (inhibition of osteoclasts or vascularization), ${ }^{80)}$ while Clo is reported to exhibit anti-tumour effects even upon oral administration. ${ }^{81,82)}$ As described in Section 3, the major mechanism underlying cytotoxicity differs between $\mathrm{N}-\mathrm{BPs}$ and Clo. Thus, when Clo and an N-BP are taken into tumour cells, a synergistic anti-tumour effect might be expected. Use of a combination of Clo with an N-BP should thus be an attractive theme for future studies.

Table 3. Previously Proposed Strategies against BRONJ

\begin{tabular}{llc}
\hline \hline & Methods & Recent typical references \\
\hline (i) & Fluorescence-guided curettage of & $73)$ \\
& necrotic bones \\
(ii) Local flaps using pedicled buccal fat pad & $74)$ \\
(iii) Hyperbaric oxygen therapy & $75)$ \\
(iv) Low intensity laser therapy after tooth & $76)$ \\
$\quad$ extraction & $77)$ \\
(v) Teriparatide therapy & $78)$ \\
(vi) Application of autologous platelet-rich- & \\
plasma after sequestrectomy & $59,79)$ \\
(vii) Etidronate-replacement therapy &
\end{tabular}

\section{ANALGESIC EFFECTS OF ETI AND CLO}

In animal experiments, BPs are reported to exhibit analgesic effects in which their anti-bone-resorptive effects are not involved, with the analgesic effect of Clo being stronger than those of the N-BPs Pam and Ale. ${ }^{83,84)}$ Moreover, Fujita et al. ${ }^{85)}$ found that in patients with osteoporosis and/or osteoarthritis, Eti displayed an analgesic effect that was greater than those of the N-BPs Ale and Ris. We confirmed the analgesic effects of Clo and Eti in two experimental models in mice (the writhing test and the capsaicin test). ${ }^{16)}$ In our experiments, analgesic effects were observed only for Eti and Clo among various non-BPs and N-BPs, the relative potencies being $\mathrm{Clo}>$ Eti. Surprisingly, Eti and Clo exhibit their analgesic effects at doses lower than those at which they exhibit anti-bone-resorptive effects. ${ }^{16)}$ As described in Section 7, Clo and Eti inhibit all families of phosphate transporters and again the order of potencies is Clo>Eti. ${ }^{67)}$ Glutamic acid, aspartic acid and ATP, which are known to be pain transmitters, are taken into neuronal vesicles, then released into synaptic clefts in response to pain-producing stimuli, leading to stimulation of their post-synaptic receptors and pain production. Recently, the transporters involved in the uptake of these transmitters into neuronal vesicles have been identified as members A5A9 of the SLC17 family of phosphate transporters. ${ }^{86)}$ Thus, it is likely that Eti and Clo exhibit their analgesic effects by inhibiting these transporters. Indeed, our recent study supports this idea ${ }^{17)}$ (Fig. 6).

\section{ONJ INDUCED BY DENOSUMAB}

As described above, we supposed that the cytotoxic effects of N-BPs on a variety of cells around jaw bones are mainly responsible for ONJ (Fig. 5A). However, unexpectedly, denosumab, another potent inhibitor of bone resorption, has recently been shown to cause ONJ. ${ }^{87,88)}$ Unlike N-BPs, denosumab is not cytotoxic. Thus, we speculate that potent or long-term inhibition of bone resorption by itself may also be a cause of ONJ. In this Section, we discuss this point.

In both the oral epithelium and the marrow of jawbones, cellular reproduction is rapid, and the mandible and maxilla are unique among skeletal structures because of the presence of teeth, through which they are frequently subject to infections. Oral tissues are thus vulnerable to radiation as well as to cytotoxic drugs, and immunity against infection and a generous blood supply are very important for the prevention of periodontitis and osteomyelitis. Moreover, it is widely recognized that irradiated jawbones are particularly susceptible to infection. The rare causes of ONJ are known to include radiation of the head and neck, cancer chemotherapy, local malignancy, periodontal disease, trauma, long-term glucocorticoid treatment and anti-angiogenetic drugs, ${ }^{88,89)}$ suggesting that ONJ can occur without inhibition of bone resorption. Indeed, Reid and Cornish suggested in their 2012 review that ONJ could be secondary to infection. ${ }^{90)}$

Receptor activator of nuclear factor $\kappa \mathrm{B}$ (RANK) and its ligand RANKL are key molecules not only in bone physiology, but also in immunity, pregnancy, and even in the central nervous system. ${ }^{91,92)}$ Indeed, RANKL and RANK play central roles in both osteoclastogenesis and lymph node organogenesis. RANKL is expressed not only on osteoblasts, but also 


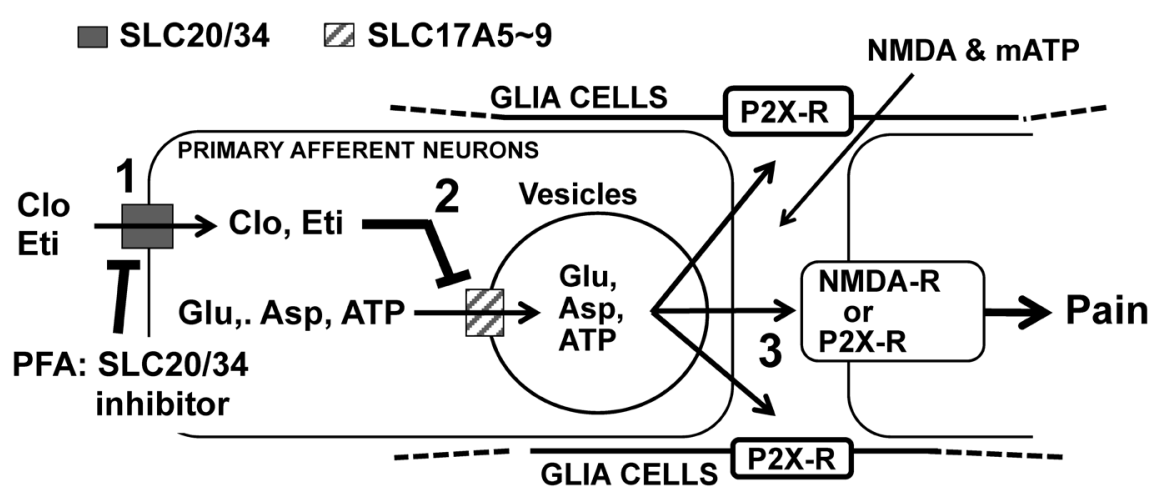

Fig. 6. Mechanisms by Which Eti and Clo Exhibit Their Analgesic Effects

Excitatory amino acids [glutamic acid (Glu) and aspartic acid (Asp)] and ATP are known to be pain neurotransmitters. Glu and Asp are taken into neuronal vesicles through SLC17A5-A8, while ATP is taken in through SLC17A9 (ref. 86). Pain stimuli induce release of these transmitters into synaptic clefts via exocytosis of the vesicles. The released Glu and Asp stimulate their receptor NMDA-R, while ATP stimulates its receptor P2X-R. Note that $N$-methyl-D-aspartate (NMDA) and $\alpha, \beta$-methylene ATP (mATP) are agonists of NMDA-R and P2X-R, respectively. We obtained the following results: (i) PFA abolishes the analgesic effects of Eti and Clo by inhibiting their entry into neurons via SLC20/34 at Step 1, (ii) Eti and Clo inhibit the transport of Glu and/or ATP via SLC17 transporters at Step 2. (iii) NMDA and mATP counteract the analgesic effects of Eti and Clo at Step 3, and (iv) SLC20 (A1 and A2) and SLC34A1 transporters are detected in neuronal tissues (ref. 17). These results support the idea that Eti and Clo may be taken into neurons via SLC20/34, and then inhibit SLCA5-A9, thereby decreasing Glu, Asp and ATP, leading to reduced pain transmission.

on activated $\mathrm{T}$ cells, dendritic cells, monocytes, macrophages, and keratinocytes. ${ }^{91,92)}$ Recent studies suggest that $\mathrm{T}$ cellderived RANKL may initiate immune system responses via activation of osteoclasts or bone loss. ${ }^{91,92)}$ Although IL-1 is considered to be the strongest cytokine for the activation of osteoclasts, we have suggested that the prime role of bone IL-1 in mice may lie in the emergency $\mathrm{Ca}^{2+}$-supply to soft tissues, not in bone-remodeling. ${ }^{93)}$ Expansion of regulatory $\mathrm{T}$ cells is also mediated by RANKL-RANK interaction, ${ }^{91,92)}$ and anti-RANKL monoclonal antibody reportedly abolishes the protective function of regulatory $\mathrm{T}$ cells, leading to increased intestinal inflammation and severe colitis in mice. ${ }^{94)}$ In addition, RANKL-RANK interaction is involved in oral immunotolerance. ${ }^{95}$ Denosumab is a human monoclonal antibody against RANKL. Thus, it seems likely that inhibition of osteoclastogenesis by denosumab, as well as the promotion of osteoclast apoptosis by N-BPs, may lead to a reduction or impairment of immunity against infection in oral tissues, inhibiting the healing of damaged oral tissues and leading to ONJ (Fig. 5B).

\section{CONCLUSION}

N-BPs are taken into soft-tissue cells via phosphate transporters. We propose mechanisms underlying BRONJ in which these transporters may play a critical role. Eti and Clo can inhibit such phosphate transporters and thus they may be effective at preventing or reducing the cytotoxicity of N-BPs. Thus, Eti and Clo may find applications in BRONJ as a substitution drug for N-BPs and a combination drug with N-BPs, respectively. Eti and Clo are drugs with both anti-bone-resorptive and analgesic effects. Many patients with osteoporosis experience pain. Thus, Eti and Clo may be safe and suitable drugs for patients with osteoporosis and/or BRONJ.

\section{PERSPECTIVES}

Among the various drugs approved for osteoporosis, N-BPs are the 1st choice drugs. However, not only are there direct inflammatory and necrotic effects on tissues exposed to N-BPs, but the bioavailability of N-BPs after oral administration is very poor. ${ }^{96)}$ Consequently, in patients with bone-metastatic tumours, N-BPs are administered mostly via intravenous drip. In osteoporotic patients, N-BPs must be taken, at the time of rising, together with $180 \mathrm{~mL}$ or more of water and the patient must avoid lying down for at least $30 \mathrm{~min}$, as well as avoiding eating, drinking, or taking other drugs. Nevertheless, lesions of the oesophagus and/or stomach occur ${ }^{97-99)}$ and many aged patients drop out from the therapy for that reason. N-BPs are also given to children with osteogenesis imperfecta. ${ }^{100)}$ Thus, safe, reliable and simple drug-delivery systems are needed for N-BPs. ${ }^{101,102)}$

In addition to BRONJ, atypical femur fracture is a serious side effect of N-BPs, ${ }^{103)}$ suggesting that the dose of N-BPs might be excessive in the patients in which it occurs. It is important to note that N-BPs accumulate within bones after repeated administrations and that the currently employed doses of N-BPs were mostly determined before BRONJ and atypical femur fractures were anticipated as adverse effects. Thus, it would seem necessary to re-evaluate both the doses of N-BPs and the term of administration.

Finally, it should be noted that the standard recipe for Eti in one cycle is $200 \mathrm{mg}$ /once a day between meals for two weeks (with no restrictions of the type required for N-BPs) followed by a 3- to 4-month rest-period, and this recipe was used in our study of the use of Eti for treating BRONJ. ${ }^{79)}$ However, since there is approval for the dose to be increased to up to $1000 \mathrm{mg} / \mathrm{d}$ and for the term to be prolonged to up to 3 months, it would be of interest in future studies to examine the utility of such high-dose recipes for treating BRONJ patients.

Acknowledgments We are grateful to the many people who joined in and/or supported this study. We are also grateful to Dr. Robert Timms, a former language-editor of $J$. Physiol. (Lond.), who edited our manuscripts throughout our studies and provided many instructive suggestions.

Conflict of Interest Yasuo Endo previously received a scholarship from Sumitomo Dainippon Pharma Co., Ltd. (Osaka, Japan). 


\section{REFERENCES}

1) Fleisch H. Diphosphonates: history and mechanisms of actions. Metab. Bone Dis. Relat. Res., 3, 279-287 (1981).

2) Marx RE. Pamidronate (Aredia) and zoledronate (Zometa) induced avascular necrosis of the jaws: a growing epidemic. J. Oral Maxillofac. Surg., 61, 1115-1117 (2003).

3) Migliorati CA. Bisphosphonates and oral cavity avascular bone necrosis. J. Clin. Oncol., 21, 4253-4254 (2003).

4) Fliefel R, Tröltzsch M, Kühnisch J, Ehrenfeld M, Otto S. Treatment strategies and outcomes of bisphosphonate-related osteonecrosis of the jaw (BRONJ) with characterization of patients: a systematic review. Int. J. Oral Maxillofac. Surg., 44, 568-585 (2015).

5) Geddes AD, D’Souza SM, Ebetino FH, Kenneth JI. Bisphosphonates: structure-activity relationships and therapeutic implications. Bone and Mineral Research (Heershe NM, Kanis JK ed.) Vol. 8, Elsevier Science BV, Amsterdam, Holland, pp. 265-306 (1994).

6) Dunford JE, Thompson K, Coxon FP, Luckman SP, Hahn FM, Poulter CD, Ebetino FH, Rogers MJ. Structure-activity relationship for inhibition of farnesyl diphosphate synthase in vitro and inhibition of bone resorption in vivo by nitrogen-containing bisphosphonates. J. Pharmacol. Exp. Ther., 296, 235-242 (2001).

7) Oizumi T, Yamaguchi K, Funayama H, Kuroishi T, Kawamura H, Sugawara S, Endo Y. Necrotic actions of nitrogen-containing bisphosphonates (NBPs) and their inhibition by clodronate (a non-NBP) in mice: potential for utilization of clodronate as a combination drug with an NBP. Basic Clin. Pharmacol. Toxicol., 104, 384-392 (2009)

8) Funayama H, Ohsako M, Monma Y, Mayanagi H, Sugawara S, Endo Y. Inhibition of inflammatory and bone-resorption-inhibitory effects of alendronate by etidronate. Calcif. Tissue Int., 76, 448457 (2005).

9) Kiyama T, Okada S, Tanaka Y, Kim S, Bando K, Hasegawa M, Yamaguchi K, Takano-Yamamoto T, Sasaki K, Sugawara S, Endo $\mathrm{Y}$. Inflammatory and necrotic effects of minodronate, a nitrogencontaining bisphosphonate, in mice. Tohoku J. Exp. Med., 230, 141-149 (2013).

10) Shima K, Tsuchiya M, Oizumi $T$, Takano-Yamamoto $T$, Sugawara $\mathrm{S}$, Endo Y. Inflammatory effects of nitrogen-containing bisphosphonates (N-BPs): modulation by non-N-BPs. Biol. Pharm. Bull., 40, 25-33 (2017).

11) Leu C-T, Luegmayr E. Freedman LP, Rodan GA, Reszka AA. Relative binding affinities of bisphosphonates for human bone and relationship to antiresorptive efficacy. Bone, 38, 628-636 (2006).

12) Nancollas GH, Tang R, Phipps RJ, Henneman Z, Gulde S, Wu W, Mangood A, Russell RGG, Ebetino FH. Novel insight into actions of bisphosphonates on bone: differences in interactions with hydroxyapatite. Bone, 38, 617-627 (2006).

13) Duan X, Xia Z, Zhang H, Quijano M, Dobson RLM, Trifitt JT, Dunford J, Ebetino FH, Russell RG. The effects of $\mathrm{pH}$ on the relative bone mineral-binding affinities of bisphosphonates determined by hydroxyapatite-column chromatography. J. Bone Miner. Res., 25 (Suppl. 1), S347 (2010).

14) Oizumi T, Funayama H, Yamaguchi K, Yokoyama M, Takahashi H, Yamamoto M, Kuroishi T, Kumamoto H, Sasaki K, Kawamura $\mathrm{H}$, Sugawara S, Endo Y. Inhibition of necrotic actions of nitrogencontaining bisphosphonates (NBPs) and their elimination from bone by etidronate (a Non-NBP): a proposal for possible utilization of etidronate as a substitution drug for NBPs. J. Oral Maxillofac. Surg., 68, 1043-1054 (2010).

15) Kiyama T, Tsuchiya M, Okada S, Oizumi T, Yamaguchi K, Sasaki K, Sugawara S, Endo Y. Phosphonocarboxylates can protect mice against the inflammatory and necrotic side effects of nitrogencontaining bisphosphonates by inhibiting their entry into cells via phosphate transporters. Biol. Pharm. Bull., 39, 712-720 (2016).

16) Kim S, Seiryu M, Okada S, Kuroishi T, Takano-Yamamoto T, Su- gawara S, Endo Y. Analgesic effects of the non-nitrogen-containing bisphosphonates etidronate and clodronate, independent of anti-resorptive effects on bone. Eur. J. Pharmacol., 699, 14-22 (2013).

17) Shima K, Nemoto $W$, Tsuchiya M, Tan-No K, Takano-Yamamoto T, Sugawara S, Endo Y. The bisphosphonates clodronate and etidronate exert analgesic effects by acting on glutamate- and/or ATP-related pain transmission pathways. Biol. Pharm. Bull., 39, 770-777 (2016).

18) Amin D, Cornell SA, Gustafson SK, Needle SJ, Ullrich JW, Bilder GE, Perrone MH. Bisphosphonates used for the treatment of bone disorders inhibit squalene synthase and cholesterol biosynthesis. $J$. Lipid Res., 33, 1657-1663 (1992).

19) Rogers MJ, Gordon S, Benford HL, Coxon FP, Luckman SP, Mönkkönen J, Frith JC. Cellular and molecular mechanisms of action of bisphosphonates. Cancer, 88 (Suppl.), 2961-2978 (2000).

20) Rogers MJ, Crockett JC, Coxon FP, Mönkkönen J. Biochemical and molecular mechanisms of action of bisphosphonates. Bone, 49 , 34-41 (2011).

21) Roelofs AJ, Thompson K, Gordon S, Rogers MJ. Molecular mechanisms of action of bisphosphonates: current status. Clin. Cancer Res., 12 (Suppl.), 6222s-6230s (2006).

22) Mönkkönen H, Auriola S, Lehenkari P, Kellinsalmi M, Hassinen IE, Vepsäläinen J, Mönkkönen J. A new endogenous ATP analog (ApppI) inhibits the mitochondrial adenine nucleotide translocase (ANT) and is responsible for the apoptosis induced by nitrogencontaining bisphosphonates. Br. J. Pharmacol., 147, 437-445 (2006).

23) van Rooijen N, van Nieuwmegen R. Elimination of phagocytic cells in the spleen after intravenous injection of liposome-encapsulated dichloromethylene diphosphonate: an enzyme-histochenical study. Cell Tissue Res., 238, 355-358 (1984).

24) Thepen T, van Rooijen N, Kraal G. Alveolar macrophage elimination in vivo is associated with an increase in pulmonary immune responses in mice. J. Exp. Med., 170, 499-509 (1989).

25) Endo Y, Nakamura M, Kikuchi T, Shinoda H, Takeda Y, Nitta Y, Kumagai K. Aminoalkylbisphosphonates, potent inhibitors of bone resorption, induce a prolonged stimulation of histamine synthesis and increase macrophages, granulocytes and osteoclasts in vivo. Calcif. Tissue Int., 52, 248-254 (1993).

26) Endo Y, Nakamura M, Nitta Y, Kumagai K. Effects of macrophage depletion on the induction of histidine decarboxylase by lipopolysaccharide, interleukin-1 and tumor necrosis factor. Br. J. Pharmacol., 114, 187-193 (1995).

27) Endo Y, Shibazaki M, Yamaguchi K, Nakamura M, Kosugi H. Inhibition of inflammatory actions of aminobisphosphonates by dichloromethylene bisphosphonate, a non-aminobisphosphonate. Br. J. Pharmacol., 126, 903-910 (1999).

28) Nakamura M, Ando T, Abe M, Kumagai K, Endo Y. Contrast between effects of aminobisphosphonates and non-aminobisphosphonates on collagen-induced arthritis in mice. Br. J. Pharmacol., 119, 205-212 (1996).

29) Nakamura M, Yagi $H$, Endo $Y$, Kosugi $H$, Ishi $T$, Itoh T. A time kinetic study of the effect of aminobisphosphonate on murine haemopoiesis. Br. J. Haematol., 107, 779-790 (1999).

30) Dinarello CA, Simon A, van der Meer JWM. Treating inflammation by blocking interleukin-1 in a broad spectrum of diseases. Nat. Rev. Drug Discov., 11, 633-652 (2012).

31) Gabay C, Lamacchia C, Palmer G. IL-1 pathways in inflammation and human diseases. Nat. Rev. Rheumatol., 6, 232-241 (2010).

32) Endo Y. Simultaneous induction of histidine and ornithine decarboxylases and changes in their product amines following the injection of Escherichia coli lipopolysaccharide into mice. Biochem. Pharmacol., 31, 1643-1647 (1982).

33) Endo Y. Induction of histidine decarboxylase in mouse tissues by mitogens in vivo. Biochem. Pharmacol., 32, 3835-3838 (1983). 
34) Endo Y, Suzuki R, Kumagai K. Macrophages can produce factors capable of inducing histidine decarboxylase, a histamine-forming enzyme, in vivo in the liver, spleen and lung of mice. Cell. Iтmиnol., 97, 13-22 (1986).

35) Endo Y. Induction of histidine and ornithine decarboxylase activities in mouse tissues by recombinant interleukin-1 and tumor necrosis factor. Biochem. Pharmacol., 38, 1287-1292 (1989).

36) Sugawara S, Shibazaki M, Takada H, Kosugi H, Endo Y. Contrasting effects of an aminobisphosphonate, a potent inhibitor of bone resorption, on lipopolysaccharide-induced production of interleukin-1 and tumour necrosis factor $\alpha$ in mice. Br. J. Pharmacol., 125, 735-740 (1998).

37) Yamaguchi K, Motegi K, Iwakura Y, Endo Y. Involvement of interleukin-1 in the inflammatory actions of aminobisphosphonates in mice. Br. J. Pharmacol., 130, 1646-1654 (2000).

38) Deng $\mathrm{X}, \mathrm{Yu} \mathrm{Z}$, Funayama H, Shoji N, Sasano T, Iwakura Y, Sugawara S, Endo Y. Mutual augmentation of the induction of the histamine-forming enzyme, histidine decarboxylase, between alendronate and immuno-stimulants (IL-1, TNF, and LPS), and its prevention by clodronate. Toxicol. Appl. Pharmacol., 213, 64-73 (2006).

39) Shikama Y, Nagai Y, Okada S, Oizumi T, Shimauchi H, Sugawara $\mathrm{S}$, Endo Y. Pro-IL-1 $\beta$ accumulation in macrophages by alendronate and its prevention by clodronate. Toxicol. Lett., 199, 123-128 (2010).

40) Adami S, Bhalla AK, Dorizzi R, Montesanti F, Rosini S, Salvagno G, Lo Cascio V. The acute phase response after bisphosphonate administration. Calcif. Tissue Int., 41, 326-331 (1987).

41) Munns CF, Rauch F, Mier RJ, Glorieux FH. Respiratory distress with pamidronate treatment in infants with severe osteogenesis imperfecta. Bone, 35, 231-234 (2004).

42) Schenk R, Eggli P, Fleisch H, Rosini S. Quantitative morphometric evaluation of the inhibitory activity of new aminobisphosphonates on bone resorption in the rat. Calcif. Tissue Int., 38, 342-349 (1986).

43) Kunzmann V, Bauer E, Feurle J, Weißinger F, Tony H-P, Wilhelm M. Stimulation of $\gamma \delta \mathrm{T}$ cells by aminobisphosphonates and induction of antiplasma cell activity in multiple myeloma. Blood, 96, 384-392 (2000).

44) Thompson K, Rogers MJ. Statins prevent bisphosphonate-induced $\gamma, \delta$-T-cell proliferation and activation in vitro. J. Bone Miner. Res., 19, 278-288 (2004).

45) Mestas J, Hughes CCW. Of mice and not men: Differences between mouse and human immunology. J. Immunol., 172, 27312738 (2004).

46) Girardi M. Immunosurveillance and immunoregulation by gammadelta T cells. J. Invest. Dermatol., 126, 25-31 (2006).

47) Mandey SH, Kuijk LM, Frenkel J, Waterham H. A role for geranylgeranylation in interleukin-1 secretion. Arthritis Rheum., 54, 3690-3695 (2006).

48) Tanaka Y, Nagai Y, Dohdoh M, Oizumi T, Ohki A, Kuroishi T, Sugawara $\mathrm{S}$, Endo Y. In vitro cytotoxicity of zoledronate (nitrogen-containing bisphosphonate: NBP) and/or etidronate (non-NBP) in tumor cells and periodontal cells. Arch. Oral Biol., 58, 628-637 (2013).

49) Bezzi M, Hasmim M, Bieler G, Dormond O, Rüegg C. Zoledronate sensitizes endothelial cells to tumor necrosis factor-induced programmed cell death. J. Biol. Chem., 278, 43603-43614 (2003).

50) Hasmim M, Bieler G, Rüegg C. Zoledronate inhibits endothelial cell adhesion, migration and survival through the suppression of multiple, prenylation-dependent signaling pathways. J. Thromb. Haemost., 5, 166-173 (2007).

51) Wu X, Yoshida A, Sasano T, Iwakura Y, Endo Y. Histamine production via mast cell-independent induction of histidine decarboxylase in response to lipopolysaccharide and interleukin 1. Int. Immunopharmacol., 4, 513-520 (2004).
52) Deng X, Yu Z, Funayama H, Yamaguchi K, Sasano T, Sugawara $\mathrm{S}$, Endo Y. Histidine decarboxylase-stimulating and inflammatory effects of alendronate in mice: involvement of mevalonate pathway, TNF $\alpha$, macrophages, and T-cells. Int. Immunopharmacol., 7 , 152-161 (2007).

53) Newton CJ, Ran G, Xie YX, Bilko D, Burgoyne GH, Adams I, Abidia A, McCollum PT, Atkin SL. Statin-induced apoptosis of vascular endothelial cells is blocked by dexamethasone. J. Endocrinol., 174, 7-16 (2002).

54) Gniadecki R. Depletion of membrane cholesterol causes ligandindependent activation of Fas and apoptosis. Biochem. Biophys. Res. Commun., 320, 165-169 (2004).

55) Monma Y, Funayama H, Mayanagi H, Endo Y. Effects of weekly administrations of alendronate+clodronate on young mouse tibia: localized action at the proximal growth plate. Calcif. Tissue Int., 74, 115-121 (2004).

56) Yu Z, Funayama H, Deng X, Kuroishi T, Sasano T, Sugawara S, Endo Y. Comparative appraisal of clodronate, aspirin and dexamethasone as agents reducing alendronate-induced inflammation in a murine model. Basic Clin. Pharmacol. Toxicol., 97, 222-229 (2005).

57) Glorieux FH, Bishop NJ, Plotkin H, Chabot G, Lanoue G, Travers R. Cyclic administration of pamidronate in children with severe osteogenesis imperfecta. N. Engl. J. Med., 339, 947-952 (1998).

58) Devogelaer JP, Malghem J, Maldague B, Nagant de Deuxchaisnes D. Radiological manifestation of bisphosphonate treatment with APD in a child suffering from osteogenesis imperfecta. Skeletal Radiol., 16, 360-363 (1987).

59) Yamaguchi K, Oizumi T, Funayama H, Kawamura H, Sugawara $\mathrm{S}$, Endo Y. Osteonecrosis of jawbones in two osteoporosis patients treated with nitrogen-containing bisphosphonate: osteonecrosis reduction by replacing NBP with non-NBP (etidronate) and rationale. J. Oral Maxillofac. Surg., 68, 889-897 (2010).

60) Buxton ILO. Pharmakokinetics and pharmacodynamics: the dynamics of drug absorption, distribution, action, and elimination. Goodman and Gilman's the pharmacological basis of therapeutics (Brunton LL, Lazo JS, Parker KL ed.). 11th edn., McGraw-Hill, New York, United State, pp. 1-39 (2006).

61) Mönkkönen J, Koponen HM, Ylitalo P. Comparison of the distribution of three bisphosphonates in mice. Pharmacol. Toxicol., 66, 294-298 (1990).

62) Szczepanska-Konkel M, Yusufi ANK, VanScoy M, Webster SK, Dousa TP. Phosphonocarboxylic acids as specific inhibitors of $\mathrm{Na}^{+}$-dependent transport of phosphate across renal brush border membrane. J. Biol. Chem., 261, 6375-6383 (1986).

63) Ullrich KJ, Rumrich G, Burke TR, Shirazi-Beechey SP, Lang $\mathrm{H}$. Interaction of alkyl/arylphosphonates, phosphonocarboxylates and diphosphonates with different anion transport systems in the proximal renal tubule. J. Pharmacol. Exp. Ther., 283, 1223-1229 (1997).

64) Virkki LV, Biber J, Murer H, Forster IC. Phosphate transporters: a tale of two solute carrier families. Am. J. Physiol. Renal Physiol., 293, F643-F654 (2007)

65) He L, Vasiliou K, Nebert DW. Analysis and update of the human solute carrier $(S L C)$ gene super family. Hum. Genomics, 3, 195206 (2009).

66) Miyamoto K, Haito-Sugino S, Kuwahara S, Ohi A, Nomura K, Ito M, Kuwahata M, Kido S, Tatsumi S, Kaneko I, Segawa H. Sodium-dependent phosphate cotransporters: lessons from gene knockout and mutation studies. J. Pharm. Sci., 100, 3719-3730 (2011).

67) Okada S, Kiyama T, Sato E, Tanaka Y, Oizumi T, Kuroishi T, Takahashi T, Sasaki K, Sugawara S, Endo Y. Inhibition of phosphate transporters ameliorate the inflammatory and necrotic side effects of the nitrogen-containing bisphosphonate zoledronate in mice. Tohoku J. Exp. Med., 231, 145-158 (2013). 
68) Funayama H, Mayanagi H, Takada H, Endo Y. Elevation of histidine decarboxylase activity in the mandible of mice by Prevotella intermedia lipopolysaccharide and its augmentation by an aminobisphosphonate. Arch. Oral Biol., 45, 787-795 (2000).

69) Deng X, Tamai R, Endo Y, Kiyoura Y. Alendronate augments interleukin-1 $\beta$ release from macrophages infected with periodontal pathogenic bacteria through activation of caspase-1. Toxicol. Appl. Pharmacol., 235, 97-104 (2009).

70) Japan Academic Society of Oral Maxillofacial Surgery. "Research on the actual condition of BRONJ therapy (in Japanese)." (2015): 〈http://www.jsoms.or.jp/medical/work/study/bronj/〉

71) Hellstein JW, Marek CL. Bisphosphonate osteonecrosis (Bisphossy Jaw): Is this phossy jaw of the 21st century? J. Oral Maxillofac. Surg., 63, 682-689 (2005).

72) Scheper MA, Badros A, Salama AR, Warburton G, Cullen KJ, Weikel DS, Meiller TF. A novel bioassay model to determine clinically significant bisphosphonate levels. Support. Care Cancer, 17, 1553-1557 (2009).

73) Pautke C, Bauer F, Otto S, Tischer T, Steiner T, Weitz J, Kreutzer K, Hohlweg-Majert B, Wolff KD, Hafner S, Mast G, Ehrenfeld M, Stürzenbaum SR, Kolk A. Fluorescence-guided bone resection in bisphosphonate-related osteonecrosis of the jaw: first clinical results of a prospective pilot study. J. Oral Maxillofac. Surg., 69, 84-91 (2011).

74) Gallego L, Junquera L, Pelaz A, Hernando J, Megias J. The use of pedicled buccal fat pad combined with sequestrectomy in bisphosphonate-related osteonecrosis of the maxilla. Med. Oral Patol. Oral Cir. Bucal, 17, e236-e241 (2012).

75) Freiberger JJ, Padilla-Burgos R, McGraw T, Suliman HB, Kraft $\mathrm{KH}$, Stolp BW, Moon RE, Piantadosi CA. What is the role of hyperbaric oxygen in the management of bisphosphonate-related osteonecrosis of the jaw: a randomized controlled trial of hyperbaric oxygen as an adjunct to surgery and antibiotics. J. Oral Maxillofac. Surg., 70, 1573-1583 (2012).

76) Vescovi P, Meleti M, Merigo E, Manfredi M, Fornaini C, Guidotti R, Nammour S. Case series of 589 tooth extractions in patients under bisphosphonates therapy. Proposal of a clinical protocol supported by Nd: YAG low-level laser therapy. Med. Oral Patol. Oral Cir. Bucal, 18, e680-e685 (2013).

77) Kim KM, Park W, Oh SY, Kim H-J, Nam W, Lim S-K, Rhee $\mathrm{Y}$, Cha IH. Distinctive role of 6-month teriparatide treatment on intractable bisphosphonate-related osteonecrosis of the jaw. Osteoporos. Int., 25, 1625-1632 (2014).

78) Pelaz A, Junquera L, Gallego L, Garcia-Consuegra L, Junquera S, Gómez C. Alternative treatments for oral bisphosphonate-related osteonecrosis of the jaws: a pilot study comparing fibrin rich in growth factors and teriparatide. Med. Oral Patol. Oral Cir. Bucal, 19, e320-e326 (2014)

79) Oizumi T, Yamaguchi K, Sato K, Takahashi M, Yoshimura G, Otsuru H, Tsuchiya M, Hagiwara Y, Itoi E, Sugawara S, Takahashi T, Endo Y. A strategy against the osteonecrosis of the jaw associated with nitrogen-containing bisphosphonates (N-BPs): attempts to replace N-BPs with the non-N-BP etidronate. Biol. Pharm. Bull., 39, 1549-1554 (2016).

80) Caraglia M, Santini D, Marra M, Vincenzi B, Tonini G, Budillon A. Emerging anti-cancer molecular mechanisms of aminobisphosphonates. Endocr. Relat. Cancer, 13, 7-26 (2006).

81) Kanis JA, Powles T, Paterson AHG, McCloskey EV, Ashley S. Clodronate decreases the frequency of skeletal metastases in women with breast cancer. Bone, 19, 663-667 (1996).

82) Diel IJ, Solomayer E-F, Costa SD, Gollan C, Goerner R, Wallwiener D, Kaufmann M, Bastert G. Reduction in new metastasis in breast cancer with adjuvant clodronate treatment. N. Engl. J. Med., 339, 357-363 (1998).
83) Bonabello A, Galmozzi MR, Bruzzese T, Zara GP. Analgesic effect of bisphosphonates in mice. Pain, 91, 269-275 (2001).

84) Bonabello A, Galmozzi MR, Canaparo R, Serpe L, Zara GP. Long-term analgesic effect of clodronate in rodents. Bone, 33, 567-574 (2003).

85) Fujita T, Ohue M, Fujii Y, Miyauchi A, Takagi Y. Comparison of the analgesic effects of bisphosphonates: etidronate, alendronate and risedronate by electroalgometry utilizing the fall of skin impedance. J. Bone Miner. Metab., 27, 234-239 (2009).

86) Omote H, Moriyama Y. Vesicular neurotransmitter transporters: an approach for studying transporters with purified proteins. Physiology, 28, 39-50 (2013).

87) Taylor KH, Middlefell LS, Mizen KD. Osteonecrosis of the jaws induced by anti-RANK ligand therapy. Br. J. Oral Maxillofac. Surg., 48, 221-223 (2010).

88) Sivolella S, Lumachi F, Stellini E, Favero L. Denosumab and antiangiogenetic drug-related osteonecrosis of the jaw: an uncommon but potentially severe disease. Anticancer Res., 33, 1793-1797 (2013).

89) Schwartz HC. Osteonecrosis of the jaws: a complication of cancer chemotherapy. Head Neck Surg., 4, 251-253 (1982).

90) Reid IR, Cornish J. Epidemiology and pathogenesis of osteonecrosis of the jaw. J. Nat. Rev. Rheumatol., 8, 90-96 (2012).

91) Sigl V, Penninger JM. RANKL/RANK_From bone physiology to breast cancer. Cytokine Growth Factor Rev., 25, 205-214 (2014).

92) Guerrini MM, Takayanagi H. The immune system, bone and RANKL. Arch. Biochem. Biophys., 561, 118-123 (2014).

93) Deng X, Oguri S, Funayama H, Ohtaki Y, Ohsako M, Yu Z, Sugawara S, Endo Y. Prime role of bone IL-1 in mice may lie in emergency $\mathrm{Ca}^{2+}$-supply to soft tissues, not in bone-remodeling. Int. Immunopharmacol., 14, 658-664 (2012).

94) Totsuka T, Kanai T, Nemoto Y, Tomita T, Okamoto R, Tsuchiya K, Nakamura T, Sakamoto N, Akiba H, Okumura K, Yagita H, Watanabe M. RANK-RANKL signaling pathway is critically involved in the function of CD4+CD25+ regulatory T cells in chronic colitis. J. Immunol., 182, 6079-6087 (2009).

95) Williamson E, Bilsborough JM, Viney JL. Regulation of mucosal dendritic cell function by receptor activator of NF-kappa B (RANK)/RANK ligand interactions: impact on tolerance induction. J. Immunol., 169, 3606-3612 (2002).

96) Porras AG, Holland SD, Gertz BJ. Pharmacokinetics of alendronate. Clin. Pharmacokinet., 36, 315-328 (1999).

97) Abraham SC, Cruz-Correa M, Lee LA, Yardley JH, Wu TT. Alendronate-associated esophageal injury: pathologic and endoscopic features. Mod. Pathol., 12, 1152-1157 (1999).

98) Graham DY. What the gastroenterologist should know about the gastrointestinal safety profiles of bisphosphonates. Dig. Dis. Sci., 47, 1665-1678 (2002).

99) Parfitt JR, Driman DK. Pathological effects of drugs on the gastrointestinal tract: a review. Hum. Pathol., 38, 527-536 (2007).

100) Eghbali-Fatourechi G. Bisphosphonate therapy in pediatric patients. J. Diabetes Metab. Disord., 13, 109 (2014).

101) Kusamori K, Katsumi H, Abe M, Ueda A, Sakai R, Hayashi R, Hirai Y, Quan YS, Kamiyama F, Sakane T, Yamamoto A. Development of a novel transdermal patch of alendronate, a nitrogencontaining bisphosphonate, for the treatment of osteoporosis. $J$. Bone Miner. Res., 25, 2582-2591 (2010).

102) Aderibigbe B, Aderibigbe I, Popoola P. Design and biological evaluation of delivery systems containing bisphosphonates. Pharmaceutics, 9, 2 (2017).

103) Saita Y, Ishijima M, Kaneko K. Atypical femoral fractures and bisphosphonate use: current evidence and clinical implications. Ther. Adv. Chronic Dis., 6, 185-193 (2015). 